\title{
Thoracic Synostosis Associated with Secondary Scoliosis in Arabian Horse Foal
}

\author{
Ahmed F Almomany ${ }^{1}$ and Musa A Alshehabat ${ }^{2 *}$ \\ ${ }^{1}$ Equine Surgery Resident, So-Cal Equine Hospital, California, Norco, USA \\ ${ }^{2}$ Assistant Professor, Department of Veterinary Clinical Sciences, Faculty of \\ Veterinary Medicine, Jordan University of Science and Technology, Irbid, Jordan \\ *Corresponding Author: Musa A Alshehabat, Assistant Professor, Department of \\ Veterinary Clinical Sciences, Faculty of Veterinary Medicine, Jordan University of \\ Science and Technology, Irbid, Jordan.
}

Received: March 20, 2020

Published: April 29, 2020

(C) All rights are reserved by Ahmed F

Almomany and Musa A Alshehabat.

\begin{abstract}
Congenital or acquired skeletal malformations of the vertebral column of horses are very rare in horses. Thoracic synostosis associated with scoliosis is a rare condition in equine practice. Synostosis is fusion of two or more bones while scoliosis is lateral curvature of the spine. We are reporting thoracic synostosis associated with scoliosis in an Arabian filly. Physical examination revealed obvious deviation of the thoracic section to the left side. Observational gait analysis did not show any gross abnormalities. Neurological examination showed no neurological deficits in the fore or the hind limbs. Radiography was essential to characterize the malformations which showed synostosis of the thoracic vertebrae (T11, T12 and T13). Follow up evaluation of the foal, in six months, did not demonstrate any worsening in gait or neurological status and showed the filly is still ambulating normally. The owner instructed not to ride or work the presented foal. Furthermore, owner was instructed not to breed the foal.

Keywords: Thoracic; Synostosis; Scoliosis; Arabian Foal
\end{abstract}

\section{Introduction}

Deformities of the axial skeletal system are uncommon in equine practice. Synostosis is an osseous union of any two or more adjacent bones and is more commonly reported in human literature [1]. However, this condition is not commonly reported in veterinary medicine. Vertebral synostosis is a dysostosis characterized by fusion of two or more vertebral bones as a result of lack of differentiation between bones or inappropriate vertebral fusion [2]. In human medicine, vertebral synostosis has been reported to occur at different levels including cervical, thoracic and lumber vertebrae [3]. Fusion of vertebrae at the cervical level is called Klippel Feil syndrome, while fusion of the vertebrae of the lumbar vertebrae is called block vertebra [3]. Clinical manifestation of synostosis in human beings depends mainly on the location and complexity of the malformation which may be a symptomatic or may include varying degrees of clinical signs including scoliosis, functional deficit, asymmetry, dizziness and headache $[2,3]$.

Vertebral deformities are infrequently reported in horses. The most commonly reported vertebral deformities in horses are cervical deformities [4]. Information about thoracic vertebral deformities such as synostosis has not been documented in horses. To the author's knowledge, all equine reports of vertebral synostosis are limited to the cervical region. The incidence, etiology and prognosis of thoracic synostosis remains unknown and probably the etiology is multifactorial. In this case report, we describe the radiographic and clinical presentation of an Arabian foal presented with thoracic synostosis that is associated with scoliosis with no manifested clinical, orthopedic or neurological impairment.

\section{Case Presentation \\ History and clinical findings}

A 6-month-old Arabian horse filly was referred to Jordan University of Science and Technology Veterinary Teaching Hospital (JUST-VTH) for further evaluation of a primary complaint of lateral deviation of thoracic vertebral column to the left side. The filly was up to date in vaccination and did not have any other obvious skeletal deformities. The owner reported that he has noticed the deformity just few weeks after the filly was born. Previous gestations of the dam were reported to be normal for the last three years and off-springs were reportedly normal. Physical examination was unremarkable and no other skeletal abnormalities, beside the thoracic deformity, were detected. Physical examination findings only showed presence of lateral deviation of the vertebral column at the 
thoracic level to the left (Figure 1). No lameness or neurological deficit was detected during the orthopedic and neurological examination. No pain could be elicited upon digital manipulation of the deviated region. The filly demonstrated flexible maneuverability upon observational gait evaluation. Radiographic evaluation of the thorax showed thoracic synostosis. Blood work was not performed. Deworming status of the filly was not current.

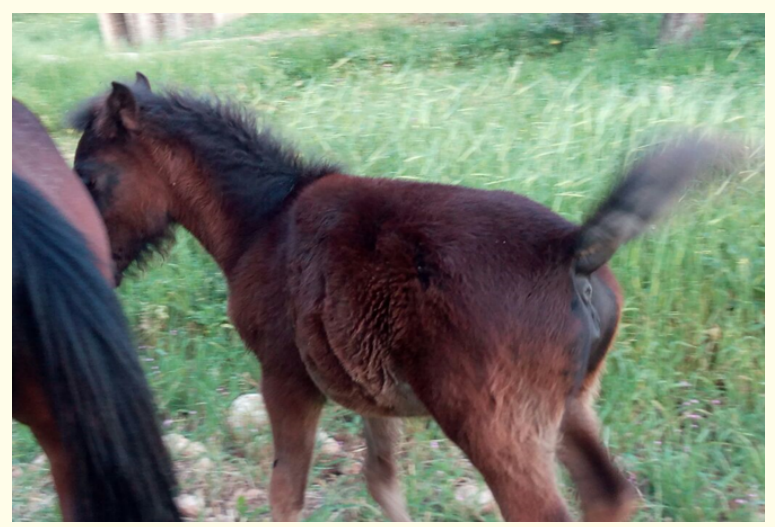

Figure 1: Photograph showing the presence of lateral deviation of the vertebral column at the thoracic level to the left side.

\section{Radiographic diagnosis}

Radiographic finding of the thoracic vertebrae illustrated in figure 2 revealed that three thoracic vertebrae are fused $\left(\mathrm{T}_{11}, \mathrm{~T}_{12}, \mathrm{~T}_{13}\right)$ to each other (synostosis). The dense appeared shortened with decreased bone opacity. Also there appears to be a slight separation between the ribs with both transverse process of the costotransverse and costovertebral joint at the level of the thoracic vertebrae $\mathrm{T}_{12}$ and $\mathrm{T}_{13}$ and possible $\mathrm{T}_{14}$. In here, only lateral radiograph could be obtained. Dorsoventral radiographic view was attempted but was not successful due to the specifications of the available radiographic machine.

\section{Discussion}

In this case report we have presented the clinical and radiographic findings of an Arabian filly diagnosed with radiographic thoracic synostosis associated with clinical scoliosis. The filly demonstrated no obvious gait abnormalities or neurological deficit. Vertebral malformations are more commonly reported in humans and dogs and less commonly in equine practices [5-8]. Information about etiology, pathogenesis, concurrent deformities, clinical presentation, and radiographic findings associated with thoracic synostosis is limited and thus the cause of this vertebral deformity remains unknown. It has been suggested that failure of vertebral

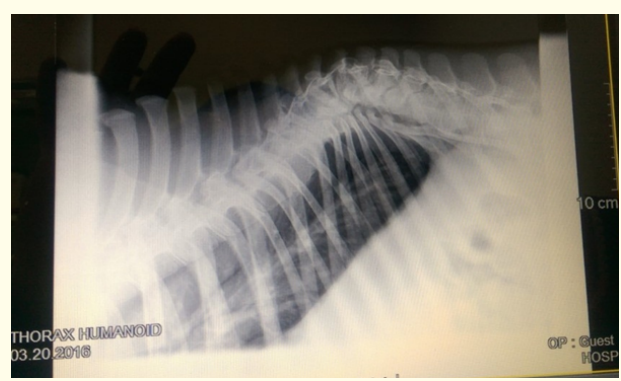

Figure 2: Lateral thoracic projection showing synostosis of $\mathrm{T}_{11}$, $\mathrm{T}_{12}, \mathrm{~T}_{13}$. Black arrows indicate slight separation between the ribs with both transverse process of the costotransverse and costovertebral joint at the level of the thoracic vertebrae $\mathrm{T}_{12}$ and $\mathrm{T}_{13}$ and possible $\mathrm{T}_{14}$.

re-segmentation might be the cause [9]. Furthermore, human cases of synostoses can potentially be caused by disease such as tuberculosis, juvenile rheumatoid arthritis and trauma [9]. In here, the clinical observation revealed that the filly also has scoliosis. Scoliosis is lateral deviation of the spine and could be related to the associated structural vertebral deformities. In human medicine, scoliosis has been often reported to be associated with pain. Vandeplassche., et $a l$. have proposed that scoliosis could be related inappropriate intrauterine environment [10]. Furthermore, scoliosis in horses has been suggested to be congenital in origin and results from malformations of the thoracic vertebrae and abnormal thoracic vertebral articulations. The scoliosis in this case may have formed because of presence of unilateral hypoplasia/aplasia of one or more intervertebral and/or costovertebral articular processes of the thoracic vertebrae. The asymmetry of the vertebral articulation(s) may have resulted in deviation of the vertebral column toward the hypoplastic side. This in turn may have increased unilateral mobility of the intervertebral articulation on the convex side and resulted in unilateral instability and the consequent lateral deviation of the vertebral column.

\section{Conclusion}

In conclusion, complete physical orthopedic and neurological examination should be performed in such cases to detect other abnormalities and determine the severity of the abnormalities. Radiography is essential diagnostic imaging modality to characterize the deformities. However, severity of radiographic malformations may not correlate well with the clinical manifestation. Since this condition may potentially be hereditary, breeding of the affected animals should be discouraged. 


\section{Bibliography}

1. Wang E., et al. "The mechanism of acute elbow flexion contracture in children with congenital proximal radioulnar synostosis". Journal of Pediatric Orthopaedics 30.3 (2010): 277-281.

2. Mudaliar RP., et al. "An Osteological Study of Occipitocervical Synostosis: Its Embryological and Clinical Significance". Journal of Clinical and Diagnostic Research 7.9 (2013): 1835-1837.

3. Sharma M., et al. "A study of vertebral synostosis and its clinical significance". Journal of Punjab Academy of Forensic Medicine and Toxicology 13 (2013): 20-24.

4. Janes JG., et al. "Cervical Vertebral Lesions in Equine Stenotic Myelopathy". Veterinary Pathology 52.5 (2015): 919-927.

5. Bouma JL. "Congenital Malformations of Vertebral Articular Processes in Dogs". Veterinary Clinics of North America: Small Animal Practice 46.2 (2016): 307-326.

6. Moore BR., et al. "Assessment of Vertebral Canal Diameter and Bony Malformations of the Cervical Part of the Spine in Horses with Cervical Stenotic Myelopathy". American Journal of Veterinary Research 55.1 (1994): 5-13.

7. Tomizawa N., et al. "Relationships between radiography of cervical vertebrae and histopathology of the cervical cord in wobbling 19 Foals". Journal of Veterinary Medical Science 56.2 (1994): 227-233.

8. Tyler CM., et al "A Survey of neurological diseases in horses". Australian Veterinary Journal 70.12 (1993): 445-449.

9. Goswami P and Yogesh Y. "Study of Thoracic Vertebral Synostosis in North India". Journal of Medical Case Reports 2.9 (2014): 170-172.

10. Vandeplassche M., et al. "Aetiology and pathogenesis of congenital torticollis and head scoliosis in the equine fetus". Equine Veterinary Journal 16.5 (1984): 419-424.

\section{Assets from publication with us}

- Prompt Acknowledgement after receiving the article

- Thorough Double blinded peer review

- Rapid Publication

- Issue of Publication Certificate

- High visibility of your Published work

Website: www.actascientific.com/

Submit Article: www.actascientific.com/submission.php

Email us: editor@actascientific.com

Contact us: +919182824667 